\title{
Ionic Mass Transfer and Concentration Polarization at Rotating Electrodes ${ }^{1}$
}

\author{
M. Eisenberg, ${ }^{2}$ C. W. Tobias, and C. R. Wilke \\ Department of Chemistry and Chemical Engineering, University of California, Berkeley, California
}

\begin{abstract}
Rates of ionic mass transfer at nickel electrodes rotating about their axes in the center of stationary electrodes were studied using the ferri-ferrocyanide couple in alkaline solutions. A general mass transfer correlation was found to apply equally well to dissolution rates of rotating solids and to rates of ionic mass transfer at rotating electrodes. This correlation takes into account physical properties of the system as well as geometrie and hydrodynamic factors. The correlation allows prediction of limiting currents and concentration polarization at rotating electrodes under a wide range of conditions.

The nature of polarization involved in reduction of $\mathrm{Fe}(\mathrm{CN})_{6}{ }^{-3}$ and oxidation of $\mathrm{Fe}(\mathrm{CN})_{0^{-4}}$ was also investigated. Polarization was found to depend strongly on the presence of electrode poisons. With freshly prepared solutions, under exclusion of light, and with cathodically treated niclsel electrodes, relatively small chemical polarizations were determined. For rotational speeds not exceeding Reynolds number 11,000, chemical polarization was found to be negligible in comparison with concentration polarization. Under such conditions, the ferro-ferricyanide couple can be conveniently used to obtain mass transfer rates for various hydrodynamic conditions, or conversely, to verify the validity of mass transfer equations by a comparison of experimental and calculated values of limiting currents and concentration polarization.

The rotating electrode model was found to be most suitable for studying the nature of electrolytic polarization phenomena because of uniformity of the current distribution and the hydrodynamic diffusion layer at the electrode surface.
\end{abstract}

\section{INTRODUCTION}

Study of mass transfer at working electrodes is of fundamental importance $(1,2)$ in analysis of electrode phenomena and in consideration of concentration polarization, limiting currents, and rates of electrode reactions. Several typical cases have been analyzed by the methods of hydrodynamics and boundary layer theory, and for a few models, experimental results were successfully correlated $(1,2)$. The effect of natural convection in electrolysis was quantitatively evaluated by Wagner (3) and Wilke and coworkers (4) among others. Rotating disk electrodes were treated mathematically by Levich (5). This theory applies if the diffusion boundary layer at the disk is laminar. Along the lines suggested by Agar (6), Lin and coworkers (7) correlated limiting current densities for the inner electrode of an annular cell with streamline and turbulent longitudinal flow. An extension of this study for laminar and turbulent flow along flat plate electrodes was recently reported (8).

The present investigation is concerned with cylindrical central electrodes rotating in concentric

\footnotetext{
${ }^{1}$ Manuscript received December 16, 1953. This paper was prepared for delivery at the Chicago Meeting, May 2 to 6,1954 .

2 Present address: Stanford Research Institute, Stanford, California.
}

cylindrical cells. Among many possible methods of stirring, the case of a rotating electrode is noteworthy, not only because it affords experimental reproducibility, but also because it permits application of methods of hydrodynamics and mass momentum transfer analogy in interpretation and corrclation of data (9-11). Theoretical analysis of this problem for electrodes is further facilitated by uniformity of current distribution resulting from the geometry of concentric cylindrical electrodes and uniform thickness of the diffusion layer formed on the rotating electrode.

Recently, rotated electrode surfaces have been used in chemical analysis and in corrosion studies in parallel with polarographic methods (12, 13). Industrial applications of this forced convection model are known, and further important uses are anticipated.

The effect of speed of rotation upon rate of mass transfer was first studied by Brunner $(14,15)$. He found that the diffusion layer thickness, $\delta{ }^{3}$ decreases with the $2 / 3$ power of the speed. However, he considered neither the effect of rotor diameter nor the dependence on physical properties of the electrolyte. Therefore, only qualitative conclusions can be drawn from these experimental results.

\footnotetext{
${ }^{3} \mathrm{~A}$ table of nomenclature is collected at the end of this
} paper. 
Eucken (16) analyzed the effect of laminar flow forced convection upon rate of mass transfer at an electrode. In his experiments the external vessel containing the solution was rotated, and laminar flow past the fixed inner flat plate electrode resulted. Eucken's mathematical analysis is valid only for this particular condition. Kambara and coworkers (17) adapted Eucken's treatment to a 0.5 -mm diameter platinum wire electrode projecting perpendicularly $6 \mathrm{~mm}$ from the axis of a rotating glass rod. In the derivation, it is assumed that the velocity gradient at the electrode surface is proportional to $\mathrm{rpm}$. This is valid for Eucken's model, where laminar flow exists in the entire region of flow, but is inadmissible for the turbulent flow case, where laminar flow is restricted to the boundary layer adjacent to the electrode surface.

For the sake of clarity, the term "rotating electrode" is used henceforth only in reference to cylindrical electrodes rotating about their axes in the center of stationary, circular, cylindrical electrodes. Recently, Roald and Beck (18) used such rotating electrodes in a study of dissolution rates of magnesium and its alloys in hydrochloric acid solutions. They found that rates of dissolution increase in low acid concentrations with the 0.71 power of the speed of rotation. At higher acid concentrations (1.4M and higher), the reaction rates become entirely independent of rotational speeds, as the stirring effect produced by hydrogen bubbles evolving at the metal interface becomes predominant. This stirring effect, however, should not be ignored even at low acid concentrations because of turbulence caused by hydrogen bubbles moving in the boundary layer adjacent to the dissolving magnesium rod. For this reason the work of Roald and Beck represents a rather special case of forced convection mass transfer.

In studies of dissolution and corrosion rates of rotated metal rods, King and coworkers (19-22) estimated the mass transfer coefficients employing King and Shack's earlier experimental finding (23), according to which "normal diffusion (or transport) control requires that rates be linear with peripheral speed above about $5000 \mathrm{~cm} / \mathrm{min}$ " (22). King and Cathcart (24) indicated that the mass transfer coefficient is directly proportional to the 0.7 power of the diffusion coefficient of the reacting ionic species.

The effect of cylinder diameter, speed of rotation, diffusion coefficient, and viscosity on mass transfer rates has not been successfully incorporated into a single correlation, although the usefulness of the Chilton-Colburn analogy for correlating the pertinent variables was realized by King and coworkers in 1937 (25).

The present work was undertaken with the follow- ing aims in mind: $(a)$ to establish correlations between physical properties of a system, geometrical and hydrodynamic conditions, and rates at which a solute (ion) is transferred to or from a rotating electrode; $(b)$ to determine whether such general mass transfer correlations enable prediction of concentration polarization and limiting currents in steady state electrolysis.

\section{Experimental}

To assure the latter objective it was important to choose an electrode reaction which occurs with negligible chemical polarization. For such an electrode process the total measured polarization $\left(\Delta E_{T}\right)^{3}$ would represent concentration polarization $\left(\Delta E_{\text {conc }}\right)$ only, and would make a comparison between theoretical prediction and experiment possible. However, most of the known electrode reactions take place with considerable chemical polarization $\left(\Delta E_{\text {chem }}\right)$ when finite currents are passed. Some oxidation-reduction reactions have long been suggested by investigators $(26-28)$ to occur with negligible chemical polarization. Recently, Moll (29) found no measurable chemical polarization for the ferrous-ferric couple at gold and platinum electrodes freshly treated by hydrogen and oxygen discharge. Essin and coworkers (30) made similar studies on the ferrocyanide-ferricyanide couple at platinum and nickel electrodes and concluded that there is no appreciable chemical polarization "when the metal is free of all film that may form on the surface." In contrast, Carmody and Rohan (31) reported a measurable chemical polarization for this latter system on platinum. A similar conclusion was arrived at by Petrocelli and Paolucci (32) who studied this couple up to current densities of 25 $\mathrm{ma} / \mathrm{cm}^{2}$. They found, however, that "cathodic activation," i.e., a hydrogen discharge treatment of the electrode, tends to decrease chemical polarization.

For the purposes of this study, smoothness of the electrode surface was important because of bydrodynamic considerations. In a redox electrolysis, unlike in a metal deposition process, the electrode surface remains physically unaltered. Another advantage of the redox reaction is that steady-state electrode potentials are attained in much shorter time than in a deposition reaction.

These findings, in addition to stability considerations of several contemplated couples, resulted in selection of the ferricyanide-ferrocyanide couple and nickel electrodes for the present studies. A large excess of sodium hydroxide was used in order to eliminate the contribution of ionic migration to mass transfer ( 1 ).

Solutions of potassium ferri- and ferrocyanide, 


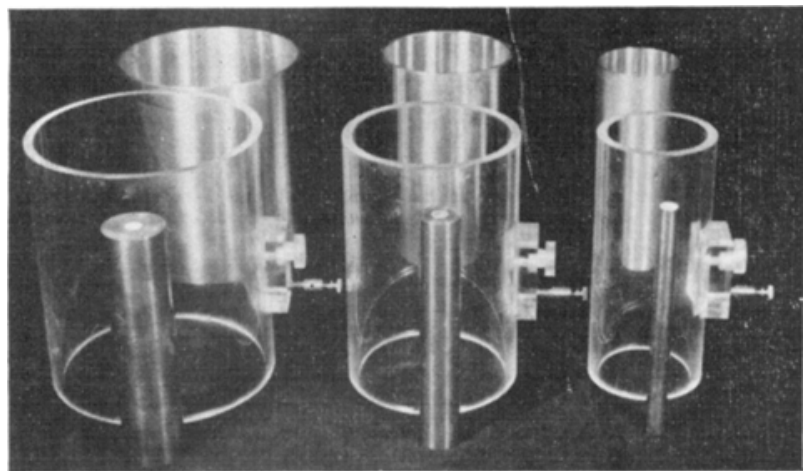

FIg. 1. Lucite cylinders, outer and inner nickel electrodes.

and particularly the ferrocyanide, are known to decompose slowly in light, resulting in formation of cyanide and hydroxide ions according to the following equations $(33,34)$ :

$$
\begin{aligned}
& {\left[\mathrm{Fe}(\mathrm{CN})_{6}\right]^{-4}+\mathrm{H}_{2} \mathrm{O} \underset{\text { dark }}{\stackrel{\text { light }}{\rightleftarrows}}\left[\mathrm{Fe}(\mathrm{CN})_{5}\right]^{-3}+\mathrm{CN}^{-}} \\
& \mathrm{CN}^{-}+\mathrm{H}_{2} \mathrm{O} \rightleftarrows \mathrm{HCN}+\mathrm{OH}^{-}
\end{aligned}
$$

In alkaline solutions kept in darkness, decomposition of these cyanide complexes is practically eliminated (35). Solutions used in these studies were freshly prepared for each series of runs in black Jena glass bottles.

\section{Apparatus and Procedure}

A concentric cylindrical cell, 6.16 in. high, built from acrylic plastic (Lucite), was equipped with grooved endplates which could hold as desired one of three cylindrical plastic tubes of $2.48,4.00,5.47$ in. ID (Fig. 1 and 2). A 1/2-in. diameter stainless steel driving shaft passing through a teflon packing gland in the top plate was equipped with a $1 / 4$-in. standard thread allowing nickel electrodes of 1.273 , 2.48 , and $5.024 \mathrm{~cm}$ diameter to be screwed onto it. The rotated electrode was supported from below by a guide pin and teflon lining in order to eliminate eccentric motion. Concentric outer cylindrical nickel electrodes of $6.07,9.87$, and $13.69 \mathrm{~cm} \mathrm{ID}$, all

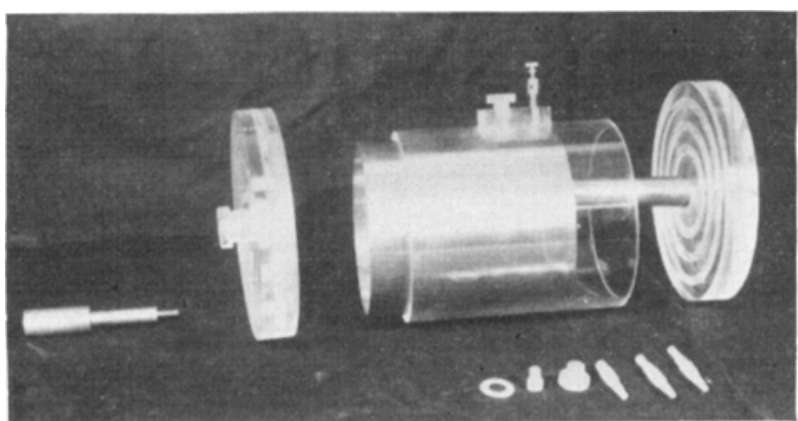

Fig. 2. Components of the cell

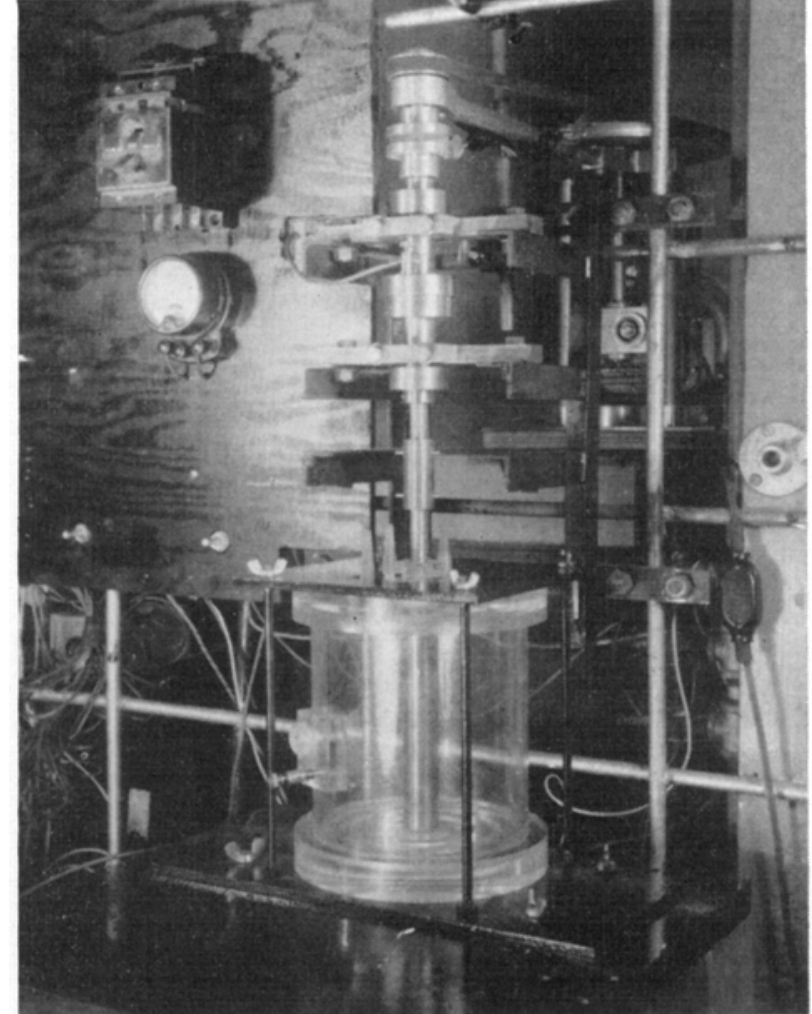

FIG. 3. Cell with supporting structure. (Outer electrode removed.)

$15.11 \mathrm{~cm}$ long, were fitted tightly into corresponding Lucite tubes (Fig. 1 and 2). The cell was made liquid tight with neoprene rubber gaskets placed in the grooves. A ground glass joint thermometer fitted into the top plate with its bulb reaching about $3 / 4$ in. into the cell. The assembled cell with supporting structure designed to eliminate vibrations is shown in Fig. 3.

Electrodes permitted a variation of the ratio of gap to the diameter of the inner electrode ranging from 0.104 to 4.88. A Lucite nipple on the top

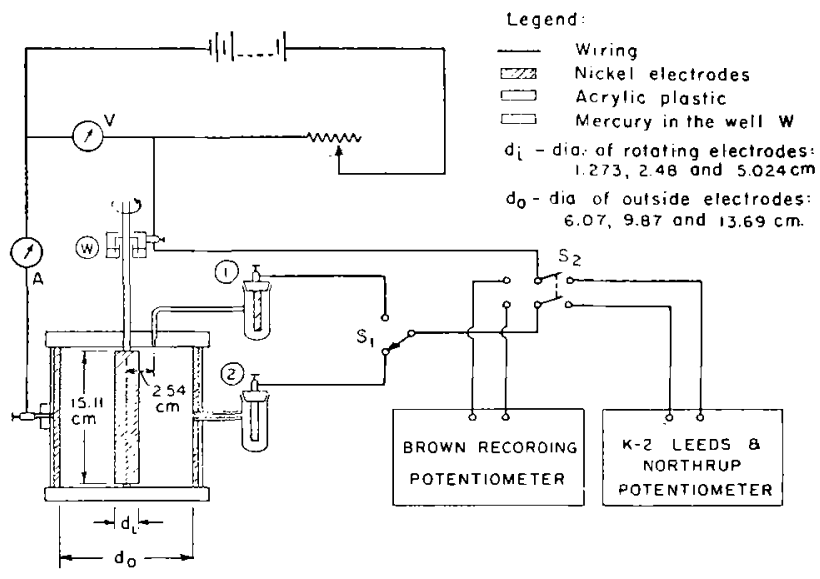

FIg. 4. Schematic diagram of the electrolyzing and measuring circuits used with the cell for rotating electrodes. 
plate of the assembled cell was screwed into a small tapered hole which ended with a $1 / 4 \mathrm{~mm}$ diameter on the inside of the plate and was located $2.541 \mathrm{~cm}$ from the cell axis (Fig. 4). Through this hole and a piece of polyethylene tubing, a continuous liquid junction led to reference cell No. 1 equipped with a nickel electrode and filled with the same solution as that in the electrolytic cell. Reference cell No. 2 was connected with the cell by means of a teflon nipple ( $1 / 4$-in. OD) leading through the center of the Lucite cylinder and ending flush with the inner surface of the outside electrode. Such arrangements of the liquid junction leading to reference electrodes are preferable for two reasons: $(a)$ the flow pattern in the cell remains undisturbed, and $(b)$ a distortion of current distribution over the electrode surface is avoided.

As can be seen from the diagram in Fig. 4, a potential measurement of the rotating electrode by means of reference electrode No. 1 involved an ohmic potential drop over the annular solution space between the radius of the rotating electrode and the distance of $2.54 \mathrm{~cm}$ at which the small opening leading to that reference cell was located. For a total current, $i$, this ohmic drop was therefore

$$
i R_{(1)}=\frac{i}{2 \pi \kappa h^{\prime}} \ln \frac{2.54}{r_{i}}
$$

where $R_{(1)}=$ resistance, ohms; $r_{i}=$ radius of rotated inner electrode, $\mathrm{cm} ; h^{\prime}=$ height of cell, here $15.11 \mathrm{~cm} ; \kappa=$ conductivity of solution, $\mathrm{ohm}^{-1}$ $\mathrm{cm}^{-1}$.

Similarly a potential measurement of the rotated electrode by means of reference No. 2 involved an ohmic drop given by:

$$
i R_{(2)}=\frac{i}{2 \pi \kappa h^{\prime}} \ln \frac{r_{o}}{r_{i}}
$$

Since $r_{o}$, internal radius of the outer electrode, was either $6.84,4.94$, or $3.035 \mathrm{~cm}$, respectively, for series of runs I, II, and III, the ohmic drop could be computed more reliably by equation $(\mathrm{I} b)$, i.e., using reference No. 2. This is particularly true since a small geometrical misalignment will cause a lesser relative error in the ratio $r_{o} / r_{i}$ of equation (Ib).

In all runs, potential measurements of the rotating electrode were taken by means of both reference junctions selected one at a time with switch S-1 (Fig. 4). Net values obtained after subtracting $i R_{(1)}$ and $i R_{(2)}$ drops, respectively, rarely differed by more than $1 \%$. However, for reasons stated above, in most cases measurements with reference electrode No. 2 were preferred over an arithmetic average of the two measurements.

Electrical connection to the rotating electrode was accomplished by means of a mercury well (W in Fig. 4). A copper contact screw provided the connection to the outer stationary electrode. Current was measured with a d-c milliammeter ${ }^{4}$ or a d-c ammeter. ${ }^{5}$ All ammeters were carefully calibrated by means of standard resistors. Selector switch S-2 (Fig. 4) permitted measurements of potential by either $(a)$ recording potentiometer ${ }^{6}$ with five ranges, the largest being up to $500 \mathrm{mv}$, or a (b) manual potentiometer, ${ }^{7}$ using a high sensitivity galvanometer as zero instrument. ${ }^{8}$ The recorder was used first to ascertain whether steady-state polarization was achieved, then the final value was measured accurately by means of the manual potentiometer.

Sodium hydroxide, $2 N$, was used as neutral electrolyte in preparing five approximately equimolar potassium ferricyanide and potassium ferrocyanide solutions in the concentration range of 0.009 to 0.204 mole/l. C.P. reagents ${ }^{9}$ were used throughout. Slight changes in concentrations of ferri- and ferrocyanide ions, caused by use of a solution up to limiting current densities, were followed up by strict analytical control. Ferricyanide was determined by the iodometric procedure (36) and ferrocyanide by permanganate titration (37).

Before introduction into the cell, each solution was alternately deaerated in a glass column by means of vacuum, and saturated with nitrogen several times to remove dissolved oxygen. Presence of a considerable amount of dissolved oxygen in the cell would have interfered with electrode reactions of ferricyanide and ferrocyanide, particularly at low concentrations. Furthermore, it was felt that, in absence of oxygen, nickel electrodes would remain in an "active" state longer.

Prior to each assembling of the cell, smooth electrodes were polished with rouge paper, washed with $\mathrm{CCl}_{4}$, and treated cathodically in a $5 \% \mathrm{NaOH}$ solution at a current density of $20 \mathrm{ma} / \mathrm{cm}^{2}$ for $12-15 \mathrm{~min}$.

The assembled cell was filled with a given solution at approximately $25^{\circ} \mathrm{C}$, the inner electrode set into rotation at a selected speed. Value of the electrode potential at no current flow $(Z C P)$ was measured with both references. These were later subtracted (with proper sign) from the "at current" values. Thus any "static" potential differences due to variations in surface structure of the electrodes could be accounted for. A relatively small current was applied, and the potential of the rotating elec-

\footnotetext{
${ }^{4}$ Weston (Model 45).

${ }^{5}$ Cenco (Model 6935).

${ }^{6}$ Minneapolis Honeywell Company (Model Y-153-X-12).

${ }^{7}$ Leeds and Northrup, Type K-2 (Model No. 7552).

${ }^{8}$ Leeds and Northrup (No. 2430).

${ }^{9}$ Merck and Company.
} 
trode followed with a reference electrode and recording potentiometer until steady state was achieved. Final values were then measured with the manual potentiometer, using both reference electrodes consecutively. Steady-state polarization was obtained in a few seconds at high speeds and within 2-3 min at low speeds. Achievement of the steady state, while not essential for determination of limiting currents, was important for subsequent calculations of chemical polarization. A reliable comparison of concentration and chemical polarization can be made only under steady-state conditions. Current was increased in small increments until the limiting current, noted by a sudden rise in potential, was attained. At a given speed each run was first completed with the rotor as cathode. Then polarity was reversed and a run was carried out with the rotor as anode. When a series of runs with speeds ranging from 30 to $1650 \mathrm{rpm}$ was complete, the cell was taken apart, the electrodes treated as described previously, and reassembled with another electrode diameter but with the same inner electrode. Thus the effect of the gap between concentric cylindrical electrodes was studied for a given solution, given diameter of rotating electrode, and given angular velocity. The temperature of $25^{\circ} \mathrm{C} \pm 0.3$ was maintained by blowing preheated or precooled air on the cell exterior. Physical properties required for correlative study were determined for each solution within the range $20^{\circ}-30^{\circ} \mathrm{C}$.

Conductivities were measured in a conventional conductivity cell, calibrated with $0.9996 \mathrm{M} \mathrm{KCl}$ solution, using an audiooscillator ${ }^{10}$ as power source for 1000 cycle A.C., a Wheatstone bridge, and an oscilloscope ${ }^{11}$ as zero instrument.

Viscosities of solutions relative to water were measured at several temperatures in a thermostat with an Ubbelohde pipette, and absolute viscosities calculated using densities obtained by pycnometer determinations.

Diffusion coefficients for ferri-ferrocyanide ions were measured by the capillary method (38).

\section{Methods of Calculation}

Ionic mass transfer.-Potential values obtained for each run were first corrected by subtracting (with proper sign) the $Z C P$ differences and the corresponding $i R$ drops calculated by means of equation (I). These net resulting values represented $\Delta E_{T}$. From the known areas of rotating electrodes, current densities were calculated, and plots of current density, $I\left(\mathrm{ma} / \mathrm{cm}^{2}\right)$ vs, $\Delta E_{T}(\mathrm{mv})$ were prepared. Limiting current densities were then determined. for each run at the plateau of the curve. At this

\footnotetext{
10 Hewlett-Packard Model $200 \mathrm{C}$.
}

11 RCA No. 155 A. point, in case of cathodic ferricyanide reduction runs, the consecutive electrode process was hydrogen evolution. This, however, did not take place before the potentials exceeded 600-700 mv. For anodic oxidation of ferrocyanide the plateau was shorter as the consecutive reaction (oxygen evolution) took place at $\Delta E_{T}$ values of $200-250 \mathrm{mv}$. As illustrations, Fig. 5 and 6 show sets of cathodic and corresponding anodic runs for solution No. 9 at speeds up to $1650 \mathrm{rpm}$. The limiting cathodic current densities $\left(I_{c}\right)$ and the limiting anodic current densities $\left(I_{a}\right)$ are given in the corresponding figures.

At limiting current when interfacial concentration of reacting species becomes zero, the rate of ionic mass transfer of ferricyanide ion to the cathode or of ferrocyanide ion to the anode can be expressed as (1):

$$
N=\frac{I_{L}}{n \overline{\mathbf{F}}}\left(1-t_{i}\right)=k_{L} c_{o}
$$

where $I_{L}=$ cathodic $\left(I_{c}\right)$ or anodic $\left(I_{a}\right)$ limiting current densities, $\operatorname{amp} / \mathrm{cm}^{2} ; n=$ valence change of reacting ion; $\mathbf{F}=$ the Faraday constant; $c_{0}=$ bulk concentration of reacting ion, moles/ce; $t_{i}=$ transference number of the reacting ion; $k_{L}=$ average mass transfer coefficient, $\mathrm{cm} / \mathrm{sec}$. Since the estimated transference numbers of ferri- and ferrocyanide ions did not exceed 0.03 (and was usually much lower) due to excess $\mathrm{NaOH}$ used as the indifferent electrolyte, equation (II) can be rewritten as:

$$
N=\frac{I_{L}}{n \mathbf{F}}=k_{L} c_{o}
$$

Thus by means of equation (II $a$ ) the average mass transfer coefficient, $k_{c}$ for the ferricyanide reduction and $k_{a}$ for ferrocyanide oxidation, was calculated for each run.

From the measured values of viscosity, $\mu$, density, $\rho$, and diffusion coefficients, $D$, of ferrous and ferric cyanide, corrected to the temperature of given runs, the corresponding Schmidt groups $S c=$ $\mu / \rho D$ were computed for anodic and cathodic experiments.

The Reynolds number, characterizing flow produced in the cell, was found to involve the rotating electrode diameter as the characteristic length dimension and not the gap between cylindrical electrodes (39). Accordingly, the Reynolds number was computed as:

$$
R_{d}=\frac{V \cdot d_{i}}{\nu}
$$

where $V=$ peripheral velocity, $\mathrm{cm} / \mathrm{sec}$; and $\nu=$ kinematic viscosity, $\mathrm{cm}^{2} / \mathrm{sec}$.

Concentration polarization and chemical polariza- 
tion.--It is clear that as far as mass transfer studies are concerned, it is not necessary for the electrode reaction to take place with negligible chemical polarization. The mass transfer coefficient, $k_{L}$, could be calculated for any current density if in addition to the bulk concentration, $c_{o}$, the interfacial concentration, $c_{i}$, were known. Since an accurate experimental determination of $c_{i}$ is extremely difficult, mass transfer coefficients are most conveniently obtained from limiting current measurements, as outlined above.

However, an electrode reaction with negligible chemical polarization was desirable in these studies in order to ascertain experimentally whether correct predictions of limiting currents and concentration polarization can be made from a general mass transfer correlation for rotating cylinders.

The ferri-ferrocyanide couple was therefore investigated as to the nature of polarization associated with both cathodic reduction of ferricyanide and anodic oxidation of ferrocyanide on nickel electrodes. This was done as follows.

(A) From graphs of $I$ vs. $\Delta E_{T}$ (of the type shown in Fig. 6 and 7 ), values of $I$ and $\Delta E_{T}$ were read off at equal current density increments and tabulated

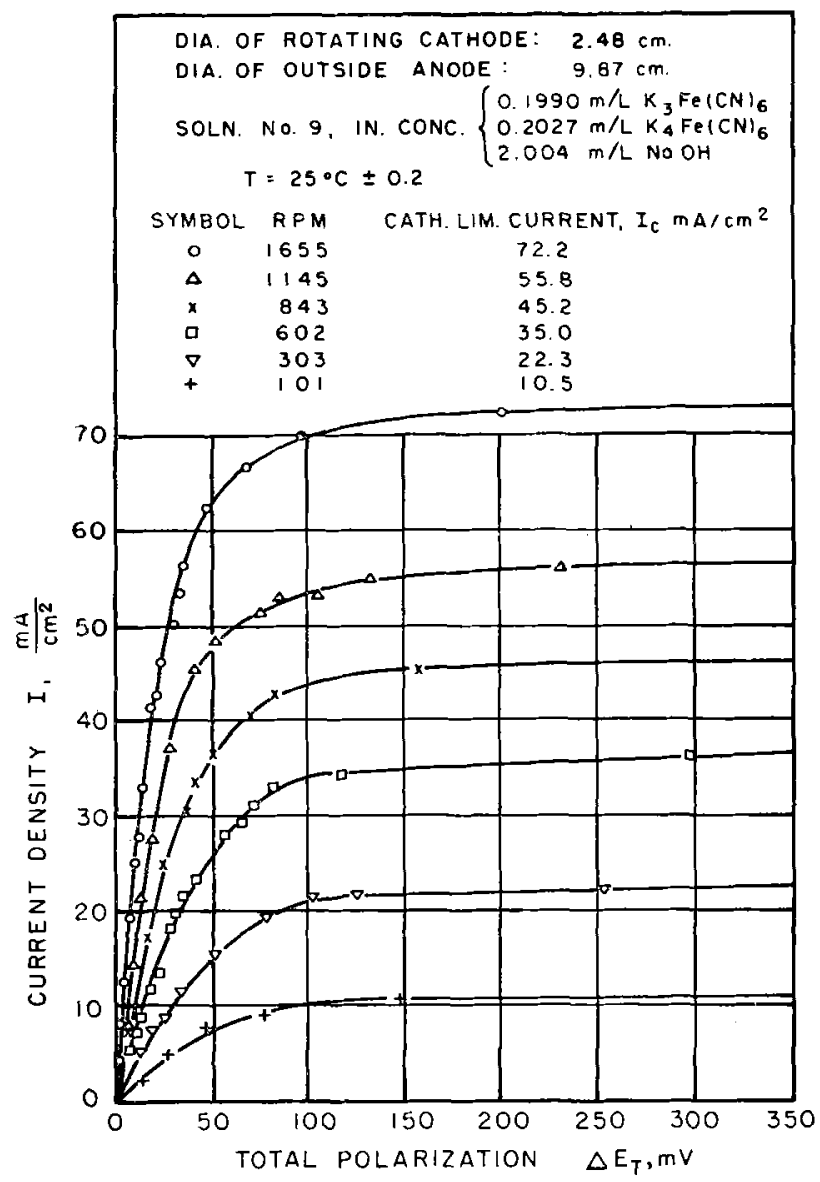

FIG. 5. Cathodic polarization curves of ferricyanide ion reduction.

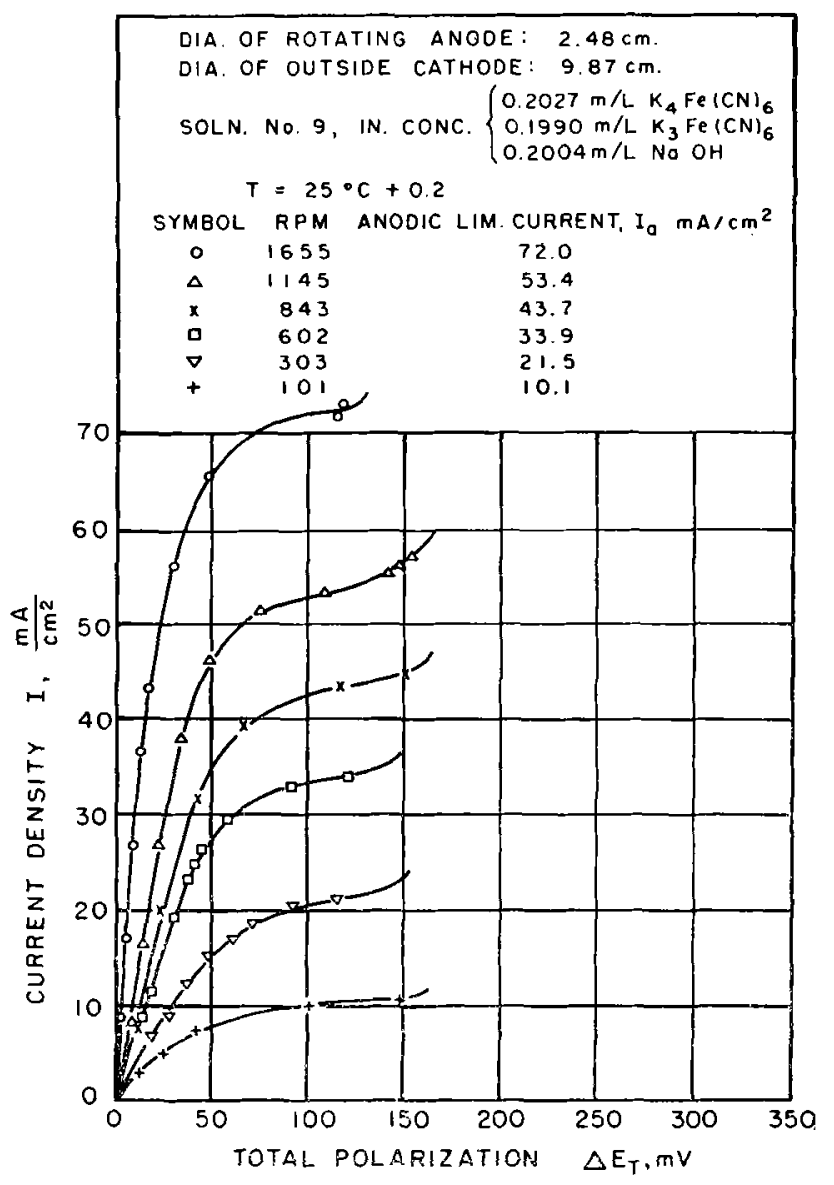

FIG. 6. Anodic polarization curves of ferrocyanide ion oxidation.

up to current densities equal to $70-75 \%$ of limiting current density.

(B) Using $I_{c}$, and $I_{a}$ (both obtained for the same solution, cell geometry and speed), $\Delta E_{\text {conc }}$ for this redox couple was calculated $(30,40)$ for each current density by the following equations ${ }^{12}$ :

$\Delta E_{\mathrm{con} \text { c }}=\frac{R T}{n \mathrm{~F}} \ln \frac{1-I / I_{c}}{1+I / I_{a}}$ (for cathodic case)

(IVa)

$\Delta E_{\mathrm{conc}}=\frac{R T}{n \mathbf{F}} \ln \frac{1+I / I_{c}}{1-I / I_{a}}$ (for anodic case)

(C) $\Delta E_{\text {chem }}$ at each of the applied current densities was calculated by subtracting the calculated $\Delta E_{\text {conc }}$ from the experimentally obtained $\Delta E_{T}$ :

$$
\Delta E_{\text {chem }}=\Delta E_{T}-\Delta E_{\text {cone }}
$$

It is interesting to note that, from equations (IV) and (V) for the case of a redox electrode reaction with negligible chemical polarization, a plot of

12 Actualiy the derivation of equation (IVa) assumes that the mass transfer coefficient is independent of current density. In forced convection such an assumption is well justified. 


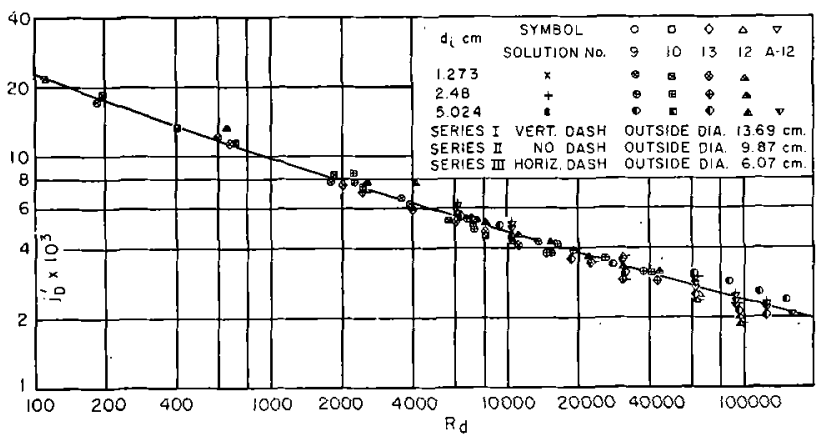

FIg. 7. Cathodic reduction of ferricyanide. Mass transfer at rotating electrodes.

$$
j_{D}^{\prime}=\frac{k_{c}}{V}\left(S_{c}\right)^{0.644} \quad \text { vs. } R_{d}
$$

experimental values of $\Delta E_{T}$ versus $\log Q$, where

$$
Q=\frac{1 \mp I / I_{c}}{1 \pm I / I_{a}}
$$

(upper sign for cathodic, lower for anodic case) should yield a straight line with slope $2.303 R T / n \mathbf{F}$. For the ferri-ferrocyanide couple $n=1$, and expressing potentials in millivolts, the slope for experiments performed at $25^{\circ} \mathrm{C}$ should be 59.1 .

\section{Results and Discussion}

\section{Correlation of Mass Transfer Rates}

Ionic mass transfer results presented here were part of a broader study involving dissolution of rotating cylinders cast from benzoic and cinnamic acid into water and aqueous glycerol solutions (39). A general type of correlation based on methods of momentum-mass transfer analogy was obtained using the following parameter:

$$
j_{D}^{\prime}=\frac{k_{L}}{V}(S c)^{0.644}
$$

in which $S c=\nu / D$ accounts for the physical properties of the system and $k_{L}$ is given by equation (II $a)$.

Fig. 7 and 8 show logarithmic $j_{D}^{\prime}$ vs. $R_{d}$ plots of mass transfer data for reduction of ferricyanide and oxidation of ferrocyanide, respectively. Table I gives a typical set of data, ${ }^{13}$ including physical properties, for one of five solutions studied. Average deviations of points in Fig. 7 and 8 from the best line are $\pm 7 \%$ and $\pm 6.6 \%$ for the two electrode reactions. These experiments involved a Schmidt number variation of 2230 to 3650 and a Reynolds number range of 112.0-162,000 (peripheral velocities 1.17 to $426 \mathrm{~cm} / \mathrm{sec}$ ). Limiting current densities varied from 0.43 to $113 \mathrm{ma} / \mathrm{cm}^{2}$.

${ }^{13}$ Complete data are given in Reference (39).

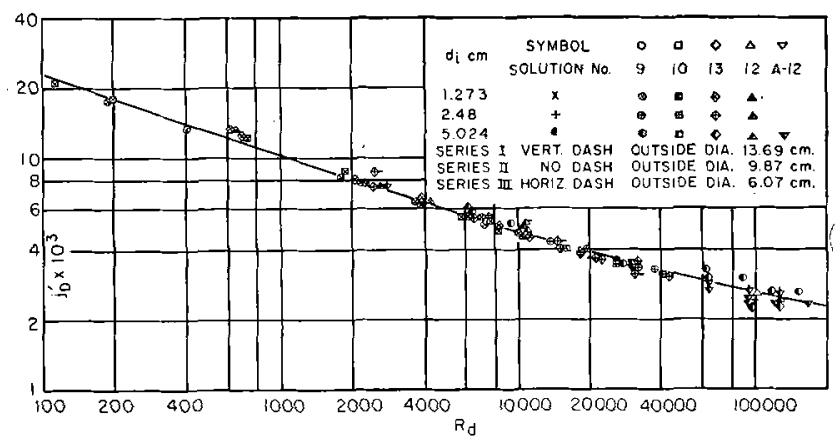

FIG. 8. Anodic oxidation of ferrocyanide. Mass transfer at rotating electrodes.

$$
j_{D}^{\prime}=\frac{k_{a}}{V}\left(S_{c}\right)^{0.644} \text { vs. } R_{d}
$$

In Fig. 9, lines correlating electrolytic data are compared with results obtained by solid dissolution studies. Results for the various systems agree with each other within $7 \%$ and all lie within experimental error involved in determination of frictional drag coefficient, $f / 2$, obtained by Theodorsen and Regier (11).

Such an agreement is very encouraging in view of the Chilton-Colburn analogy (41) which suggests that

$$
j_{D}=\frac{k_{L}}{V} \phi(S c)=f / 2
$$

where $\phi(S c)$ represents a function of the Schmidt number. [For a detailed discussion see Reference (39).

In Fig. 10, all mass transfer data for three solid dissolution systems and the two electrolytic redox reactions were plotted together. The best curve (within $\pm 8.3 \%$ ) through all points is represented by coordinates given in Table II.

In the Reynolds number range 1000-100,000 data are best represented by a straight line (dashed in Fig. 10) given by

$$
j_{D}^{\prime}=\frac{k_{L}}{V} S c^{0.644}=0.0791 R_{d}^{-0.30}
$$

From equation (IX) a number of interesting practical relations may be derived.

Recalling that the mass transfer coefficient $k_{L}=$ $I_{L} / n \mathbf{F} c_{o}$, the following relations for limiting current density may be obtained:

$$
\begin{aligned}
I_{L} & =0.0791 n \mathrm{~F} c_{o} V\left(\frac{V d_{i}}{\nu}\right)^{-0.30}\left(\frac{\nu}{D}\right)^{-0.644} \\
& =0.0791 n \mathrm{~F} c_{o} V^{0.70} d_{i}^{0.30} \nu^{-0.344} D^{0.644} \\
& =n \mathrm{~F} \frac{D c_{o}}{\delta}\left(\operatorname{amp} / \mathrm{cm}^{2}\right)
\end{aligned}
$$


TABLE I. Mass transfer at rotating electrodes, ferri-ferrocyanide couple. (Sample data). ${ }^{*}$ Solution No. 9 $(2.004 \mathrm{~N} \mathrm{NaOH})$

\begin{tabular}{|c|c|c|c|c|c|c|c|c|c|c|c|c|c|c|c|c|}
\hline \multirow[b]{2}{*}{ Run No. } & \multirow[b]{2}{*}{$V \mathrm{~cm} / \mathrm{sec}$} & \multirow[b]{2}{*}{$T^{\circ} \mathrm{C}$} & \multirow[b]{2}{*}{$\begin{array}{l}\nu \times 10^{2} \\
\mathrm{~cm}^{2} / \mathrm{sec}\end{array}$} & \multirow[b]{2}{*}{$R_{d}$} & \multicolumn{6}{|c|}{ Cathodic reduction of ferricyanide } & \multicolumn{6}{|c|}{ Anodic oxidation of ferrocyanide } \\
\hline & & & & & $\begin{array}{l}C_{\text {ferri }} \times \\
10^{3} X \\
\text { mole/cc }\end{array}$ & $\left|\begin{array}{c}I_{c} \\
\mathrm{ma} / \mathrm{cm}^{2}\end{array}\right|$ & $\left\{\begin{array}{c}k_{c} \times \\
105 \\
\mathrm{~cm} / \\
\mathrm{sec}\end{array}\right.$ & $\left|\begin{array}{c}D \times \\
10^{5} \\
\mathrm{~cm}^{2} / \\
\sec \end{array}\right|$ & $s c$ & $\mid \begin{array}{lll}j & b \\
10^{3}\end{array}$ & $\mid \begin{array}{c}C_{\text {ferro }} \times \\
1_{03}^{3} \\
\text { mole } / \mathrm{cc}\end{array}$ & $\left|\begin{array}{c}I_{a} \\
\mathrm{ma} / \mathrm{cm}^{2}\end{array}\right|$ & $\left|\begin{array}{c}k_{a} \times \\
10^{5} \\
\mathrm{~cm} / \\
\mathrm{sec}\end{array}\right|$ & $\begin{array}{r}D \times \\
105 \\
\mathrm{~cm}^{2 /} \\
\sec \end{array}$ & Sc & ${ }_{100^{3}}^{j_{b}^{\prime} \times}$ \\
\hline \multicolumn{17}{|c|}{ 13a. $d_{i}=1.273 \mathrm{~cm}$} \\
\hline,$- 276 \mathrm{~A}$ & 114.9 & 25 & 1.423 & 10,280 & - & - & - & - & - & 一 & 0.2030 & 52.0 & 265.5 & 0.390 & 3,649 & $\begin{array}{l}9.55 \\
\end{array}$ \\
\hline $277 \mathrm{C}, 278 \mathrm{~A}$ & 81.5 & 25 & 1.423 & 7,291 & 0.1988 & 42.2 & 219.8 & 0.454 & 3,134 & 4.82 & 0.2029 & 42.0 & 214.4 & 0.390 & 3,649 & 5.1 \\
\hline $280 \mathrm{C}, 281 \mathrm{~A}$ & 40.4 & 25 & 1.423 & 3,614 & 0.1982 & 28.2 & 147.3 & $0.4543^{3}$ & 3,134 & 6.51 & 0.2028 & 26.0 & 132.6 & 0.390 & 3,649 & 6.46 \\
\hline $284 \mathrm{C}, 285 \mathrm{~A}$ & 20.0 & 25 & 1.423 & 1,789 & 0.1976 & 16.6 & 87.0 & 0.4543 & 3,134 & 7.76 & 0.2027 & 16.4 & 83.9 & 0.390 & 3,649 & 8.27 \\
\hline $286 \mathrm{C}, 287 \mathrm{~A}$ & 6.8 & 25 & 1.423 & 608 & 0.1971 & 8.8 & 46.2 & 0.4543 & 3,134 & 12.1 & 0.2026 & 8.9 & 45.4 & 0.390 & 3,649 & 13.1 \\
\hline $790 \mathrm{C}, 291 \mathrm{~A}$ & 2.07 & 25 & 1.423 & 185 & 0.1961 & 3.75 & 519.9 & $\left.0.454\right|^{3}$ & 3,134 & 17.1 & 0.2024 & 3.55 & 1.8 .2 & 0.390 & 3,649 & 17.3 \\
\hline \multicolumn{17}{|c|}{ 13b. $\quad d_{i}=2.48 \mathrm{~cm}$} \\
\hline $133 \mathrm{C}, 134 \mathrm{~A}$ & 214.9 & 25 & 1.423 & 37,460 & 0.1990 & 72.2 & 376 & $|0.454| 3$ & 3,134 & $\mid 3.12$ & 0.2027 & 72.0 & 368 & $|0.390|$ & 3,649 & 3.37 \\
\hline $135 \mathrm{C}, 136 \mathrm{~A}$ & 148.7 & 25 & 1.423 & 25,920 & 0.1970 & 55.8 & 294 & $0.454\}^{3}$ & 3,134 & 3.53 & 0.2026 & 53.4 & 273 & $0.390 \mid:$ & 3,649 & 3.62 \\
\hline $137 \mathrm{C}, 138 \mathrm{~A}$ & 109.5 & 25 & 1.423 & 19,080 & 0.1960 & 45.2 & 239 & $0.454 \mid 3$ & 3,134 & 3.89 & 0.2025 & 43.7 & 224 & $|0.390|$ & 3,649 & 4.03 \\
\hline $139 \mathrm{C}, 140 \mathrm{~A}$ & 78.2 & 25 & 1.423 & 13,630 & 0.1945 & 35.0 & 186 & $\left.0.454\right|_{3} ^{3}$ & 3,134 & 4.25 & 0.2024 & 33.9 & 174 & $0.390:$ & 3,649 & 4.37 \\
\hline $141 \mathrm{C}, 142 \mathrm{~A}$ & 39.3 & 25 & 1.423 & 6,850 & 0.1935 & 22.3 & 119 & $\left.0.454\right|^{3}$ & 3,134 & 5.41 & 0.2023 & 21.5 & 110.1 & $|0.390|$ & 3,649 & 5.51 \\
\hline $143 \mathrm{C}, 1.44 \mathrm{~A}$ & 13.1 & 25 & 1.423 & 2,283 & 0.1925 & 10.5 & 57 & $\left.0.454\right|^{3}$ & , 134 & $|7.76|$ & 0.2023 & 10.1 & 51.8 & $0.390:$ & 3,649 & 7.77 \\
\hline \multicolumn{17}{|c|}{$13 \mathrm{c} . \quad d_{i}=5.024 \mathrm{~cm} \quad A=236.4 \mathrm{~cm}^{2}$} \\
\hline $484 \mathrm{C}, 485 \mathrm{~A}$ & 26.6 & 25 & 1.423 & 9,391 & 0.1891 & 13.60 & 74.5 & 0.454 & 3,134 & 5.00 & 0.2030 & 13.80 & 70.4 & $|0.390|:$ & 3,649 & 5.22 \\
\hline $486 \mathrm{C}, 487 \mathrm{~A}$ & 79.7 & 25 & 1.423 & 28,140 & 0.1904 & 27.8 & 151.3 & 0.4543 & 3,134 & 3.39 & 0.2037 & 27.40 & 139.4 & 0.390 & 3,649 & 3.44 \\
\hline $488 \mathrm{C}, 489 \mathrm{~A}$ & 172.8 & 25 & 1.423 & 61,010 & 0.1918 & 55.6 & 300.3 & $0.454 \mid 3$ & 3,134 & 3.11 & 0.2044 & 55.6 & $281.9 \mid$ & 0.390 & 3,649 & 3.21 \\
\hline $490 \mathrm{C}, 491 \mathrm{~A}$ & 246.8 & 25 & 1.423 & 87,130 & 0.1930 & 73.3 & 393.8 & 0.4543 & 3,134 & 2.84 & 0.2050 & $75.0:$ & 379.1 & $0.390:$ & 3,649 & 3.03 \\
\hline $492 \mathrm{C}, 493 \mathrm{~A}$ & 332.8 & 25 & 1.423 & 117,500 & 0.1969 & 90.4 & 475.9 & 0.4543 & 3,134 & 2.55 & 0.2024 & 87.0 & 445.4 & 0.390 & 3,649 & 2.64 \\
\hline $494 \mathrm{C}, 495 \mathrm{~A}$ & 426.2 & 25.7 & 1.405 & 152,400 & 0.1963 & 109.0 & 575.6 & 0.461 .3 & 3,048 & 2.37 & 0.2024 & 113.0 & 578.6 & $(0.396$ & 3,548 & 2.63 \\
\hline
\end{tabular}

$\delta(\mathrm{cm})$ is then given by:

$$
\begin{aligned}
\delta & =\frac{1}{0.0791 V^{0.70} d_{i}^{-0.30} \nu^{-0.344} D^{-0.356}} \\
& =12.64 \times \frac{d_{i}^{0.30} \nu^{0.344} D^{0.356}}{V^{0.70}} \\
& =99.62 \frac{d_{i}^{-0.40} \nu^{0.344} D^{0.356}}{S^{0.70}}
\end{aligned}
$$

where $D=$ diffusion coefficient, $\mathrm{cm}^{2} / \mathrm{sec}$; and $S=$ rotational speed, rpm.

Thus, $\delta$ depends not only on rotational speed, but also on rotor diameter as well as on viscosity and diffusivity. The latter three variables were not considered by Brunner (14).

Assuming $\delta$ independent of rate (i.e., of the current density), as was suggested by Agar (6), one can write:

$$
\frac{I}{n \overline{\mathbf{F}}}=\frac{D}{\delta}\left(c_{o}-c_{i}\right)
$$

\footnotetext{
* See footnote (15), p. 315.
}

Hence for a given applied C.1., $c_{i}$ may be calculated by:

$$
c_{i}=c_{o}-\frac{I}{n \mathbf{F} D} \delta
$$

$\delta$ is obtained for a given geometry, speed and physical properties of the electrolyte by equation (XI).

Previous studies relating to mass transfer at rotating electrodes were limited in scope and can be compared to the present work only in respect to functional dependence on rotational speed. Roald and Beck (18) found for rotating magnesium electrodes:

$$
k_{L}=\text { const } V^{0.7}
$$

(XIII)

This is in agreement with results of the present study since equation (XIII) can be shown to follow from equation (IX) for a given system (constant $\nu$ and $S c$ ) and given rotor diameter. Brunner (14) used rather impractical geometries and poorly defined experimental conditions; his results may be expressed in the form:

$$
k_{L}=\text { const }(\mathrm{rpm})^{2 / 3}
$$

(XIV) 


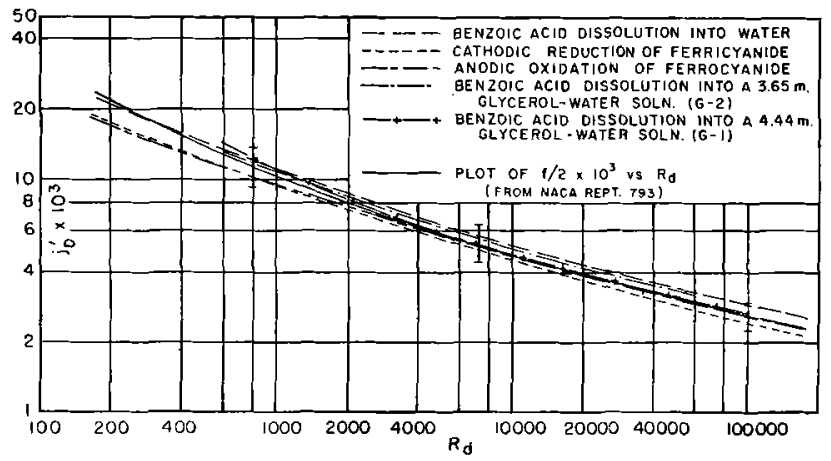

Fra. 9. Mass transfer correlation for inner rotating cylinder. Comparison of five systems studies with friction coefficients $f / 2$

For a given rotor diameter and given set of physical properties of the system, this relation is in approximate agreement with results of the present study.

A linear dependence of dissolution rates, or limiting currents on velocity of rotation as proposed by King and Shack $(22,23)$ is not substantiated by the present study.

\section{Limiting Currents and Concentration Polarization}

The nature of polarization of a redox electrode.-For $\Delta E_{r}$ of a redox electrode Petrocelli (40) obtained a general equation ${ }^{14}$ which in a somewhat modified form may be written as:

$\Delta E_{T}=\frac{R T}{n \mathrm{~F}} \ln$

$\left[\frac{1-I / I_{c}}{1+I / I_{a}}-\frac{I \frac{I_{a}}{i_{o}}}{\left(I_{a}+I\right) \exp \left(-\alpha E_{T} \frac{n F}{R T}\right)}\right]$

$(\mathrm{XV})$

where $\alpha=a$ constant between 0 and 1 (usually close to 0.5$)$ representing the portion of the electrical potential difference across the activation energy barrier, which acts in the cathodic direction; $i_{o}=$ exchange current density, representing the rate of forward (cathodic) and also backward (anodic) reaction at the reversible, or open circuit potential.

Using concepts of the absolute reaction rate theory (44) it is possible to show (40) that

$$
i_{o}=\frac{n \mathrm{~F}}{N} \frac{k T}{h} c_{o} \cdot e^{-\Delta F^{*} / R T}
$$

where $\Delta F^{*}=$ standard free energy change of the activation process (at open circuit), ergs $/$ mole; $N=$ Avogadro number, $6.023 \times 10^{23}$, molecules $/ \mathrm{mole}$; $h=$ Planck constant, $6.624 \times 10^{-27}$, erg-sec $/$ mole-

${ }^{14}$ Analogous relations have recently been obtained by a number of investigators $(42,43)$.

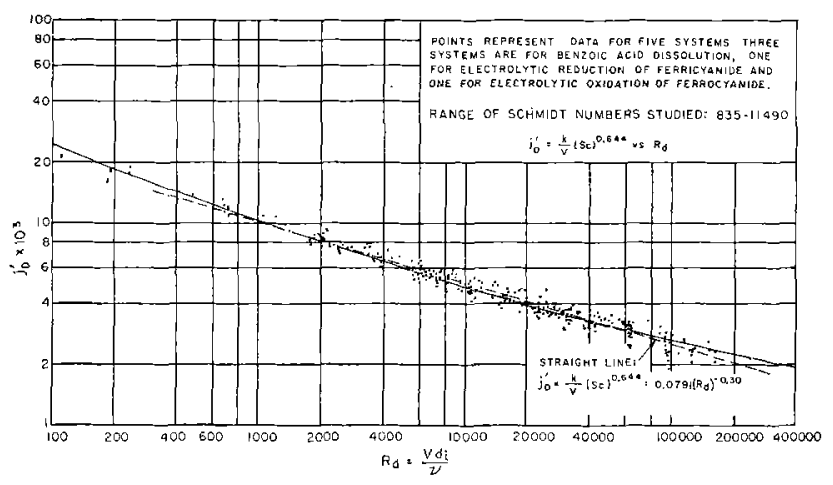

Frg. 10. General correlation for mass transfer at rotating cylinders.

cule; $k=$ Boltzmann constant, $1.3805 \times 10^{-6}$, $\mathrm{erg} /{ }^{\circ} \mathrm{K}$-molecule.

Thus, at constant $T, i_{\circ}$ depends only on $\Delta F^{*}$ and $c_{o}$, of reacting ions. For a given electrode reaction the activation energy can be assumed to be constant provided electrode poisons are absent $(29,42)$. Under such conditions $i_{o}$ depends only on $c_{o}$.

In equation (XV) the first term in the bracket represents the contribution of concentration polarization, and the second represents chemical polarization. Relative magnitude of this second term depends primarily on $I_{a} / i_{a}$.

For a given electrode system $I_{a}$ increases with the 0.70 power of the rotational velocity, according to equation $(\mathrm{X}) ; i_{o}$, however, remains unaffected. Hence at high rotational speeds, i.e., large values of $I_{a} / i_{n}$, chemical polarization should become significant in comparison with concentration polarization. It is obvious, therefore, that in order to ascertain experimentally whether a given electrolytic redox reaction comes close to thermodynamic reversibility, i.e., takes place with a comparatively small chemical polarization, $\Delta E_{T}$ vs. $I$ curves must be obtained at high rotational speeds. From such curves (see, for example, Fig. 5 and 6) plots of $\Delta E_{T}$ against $\log \frac{1 \mp I / I_{c}}{1 \pm I / I_{a}}$ can be prepared

TABLE II. Coordinates of the general mass transfer correlation curve for rotating cylinders (see Fig. 10)

\begin{tabular}{r|c}
\multicolumn{1}{c|}{$R_{d}$} & $j_{D}^{\prime} \times 10^{3}$ \\
\hline 200 & 18.4 \\
500 & 13.0 \\
1,000 & 10.2 \\
4,000 & 6.53 \\
10,000 & 4.88 \\
30,000 & 3.54 \\
60,000 & 2.96 \\
100,000 & 2.61 \\
200,000 & 2.24 \\
300,000 & 2.05 \\
\hline
\end{tabular}


as described previously. A comparison of equations (IV) and (XV) shows that if chemical polarization is negligible, i.e., $\Delta E_{T} \approx \Delta E_{\text {cono }}$, experimental points in such plots should fall close to a straight line with a slope of 59.1 (at $25^{\circ} \mathrm{C}$, expressing polarization in $\mathrm{mv}$ ). This type of plot is very convenient, as the distance of a given point from the straight line with slope 59.1 gives directly the value of chemical polarization and demonstrates its importance relative to concentration polarization (see for instance in Fig. 13).

Table III $^{15}$ gives typical results for a given concentration, inner and outer diameter. Values of $\Delta E_{\text {conc }}$ and $\Delta E_{\text {chem }}$ were calculated according to equations (IV) and (V). Data for three experimental series were plotted in Fig. 11. Solutions used were only $0.05 \mathrm{M}$ and $0.01 \mathrm{M}$ in ferri- or ferrocyanide, hence, according to equations (XV) and (XVI) some chemical polarization may be expected. However, as Fig. 11 shows, even up to peripheral velocities of $157.3 \mathrm{~cm} / \mathrm{sec}, \Delta E_{T}$ consists almost entirely, within limits of experimental accuracy, of concentration polarization.

The predominant importance of the stirring rate as represented by $V$ is interestingly demonstrated in Fig. 13 for a solution of a relatively high concentration [number 9, approximately $0.20 \mathrm{~N}$ of $\mathrm{Fe}(\mathrm{CN})_{6}^{-3}$ and $\left.\mathrm{Fe}(\mathrm{CN})_{6}^{-4}\right]$. For runs up to a velocity of 115 $\mathrm{cm} / \mathrm{sec}$, data fall close to the straight line with a slope 59.1, the value for the so-called reversible electrode. At higher speeds, i.e., when the ratio $I_{a} / i_{o}$ increases, chemical polarization becomes relatively significant. For instance at $V=333 \mathrm{~cm} / \mathrm{sec}$, when the concentration polarization is $59.1 \mathrm{mv}$, the corresponding chemical polarization has already reached $19.4 \mathrm{mv}$ (Fig. 13). Hence, in case of a reaction where $I_{a} / i_{o}$ is not very small, it is possible to increase this ratio by increasing $I_{a}$ with stirring (rotational speed). In this way a reaction in which polarization is predominantly controlled by mass transfer (i.e., concentration polarization) may be converted to one which is under activation control, involving large chemical polarization.

As shown previously, $i_{o}$ depends greatly on the activation energy necessary for the reaction to proceed. The latter has been found by many investigators to increase in the presence of electrolytic poisons $(29,42)$. Thus, according to equation (XVI),

\footnotetext{
${ }^{15}$ An extended version of these tables has been deposited as Document 4212 with the ADI Auxiliary Publications Project, Photoduplication Service, Library of Congress, Washington 5, D. C. A copy may be secured by citing the Document number and by remitting $\$ 1.25$ for photoprints, or $\$ 1.25$ for $35-\mathrm{mm}$ microfilm. Advance payment is required. Make checks or money orders payable to: Chief, Photoduplication Service, Library of Congress.
}

TABLE III. Concentration and chemical polarizations at various rotational speeds and current densities [Sample data $]^{15}$

Solution No. 13, Series II

Initial composition : $\left(0.04996 \mathrm{~m} / 1 \mathrm{~K}_{3} \mathrm{Fe}(\mathrm{CN})_{6}\right.$ $\left(0.05052 \mathrm{~m} / 1 \mathrm{~K}_{4} \mathrm{Fe}(\mathrm{CN})_{6}\right.$

$\mathrm{T}=25.0^{\circ} \mathrm{C}$ $(1.923 \mathrm{~m} / \mathrm{l} \mathrm{NaOH}$

Rotor diameter $\left(d_{i}\right)=5.024 \mathrm{~cm}$

Outer cylinder diameter $\left(d_{o}\right)=9.87 \mathrm{~cm}$

\begin{tabular}{|c|c|c|c|c|c|c|c|}
\hline \multirow[b]{2}{*}{$\begin{array}{l}\text { Run } \\
\text { No. }\end{array}$} & \multirow[b]{2}{*}{$\underset{\mathrm{ma} / \mathrm{cm}^{2}}{\mathrm{I}}$} & \multicolumn{3}{|c|}{ Cathodic reduction of $\mathrm{Fe}(\mathrm{CN})^{-3}$} & \multicolumn{3}{|c|}{$\begin{array}{l}\text { Anodic oxidation of } \\
\mathrm{Fe}(\mathrm{CN})^{-\frac{1}{6}}\end{array}$} \\
\hline & & $\begin{array}{l}\Delta E^{*} \text { onc } \\
\text { (calc) mv }\end{array}$ & $\underset{\substack{\Delta E_{T} \\
\text { mveas) }}}{\Delta E^{\prime}}$ & $\begin{array}{c}\Delta E_{\text {clem }} \\
=\Delta E_{T} \\
\Delta \overline{E_{\text {none }}} \\
\mathrm{mv}\end{array}$ & $\begin{array}{l}\Delta E^{*} \text { conc } \\
\text { (calc) } \\
\text { mv }\end{array}$ & $\begin{array}{l}\Delta E T \\
\substack{(\text { meas) } \\
\text { mv }}\end{array}$ & $\begin{array}{l}\Delta E_{\text {chem }} \\
=\Delta E_{T} \\
\vec{E}_{\text {conc }} \\
\mathrm{mv}\end{array}$ \\
\hline \multicolumn{8}{|c|}{$\begin{aligned} 1208 \mathrm{rpm} ; V= & 318 \mathrm{~cm} / \mathrm{sec} ; \quad I_{c}=22.00 \mathrm{ma} / \mathrm{cm}^{2} ; \\
& I_{a}=21.00 \mathrm{ma} / \mathrm{cm}^{2}\end{aligned}$} \\
\hline \multirow[t]{10}{*}{$15 a$} & 2 & -4.5 & -4.0 & 0.5 & 4.8 & 4.0 & -0.8 \\
\hline & 4 & -9.6 & -9 & 0.5 & 9.7 & 8.1 & -1 \\
\hline & 6 & -14.6 & -12 & 2.2 & 14.8 & 12.4 & -2.4 \\
\hline & 8 & -19.9 & -17 & 2.7 & 20.3 & 17.2 & -3.1 \\
\hline & 10 & -25 & -21 & 4.0 & 26.3 & 21.6 & -4 \\
\hline & 12 & -31.9 & -26.7 & 5.2 & 33.0 & 27.8 & -5 \\
\hline & 14 & -39.1 & -34.1 & 5.0 & 40.8 & 36.3 & -4.5 \\
\hline & 16 & -47.9 & -43.0 & 4.9 & 50.9 & 50.0 & -0.9 \\
\hline & 18 & -59.8 & -56.7 & 3.1 & 65.5 & 67.2 & 1.7 \\
\hline & 18.5 & -63.6 & -61.6 & 2.0 & 70.5 & 72.8 & 2.3 \\
\hline
\end{tabular}

\begin{tabular}{|c|c|c|c|c|c|c|}
\hline \multicolumn{7}{|c|}{$\begin{array}{c}302 \mathrm{rpm} ; V=79.4 \mathrm{~cm} / \mathrm{sec} ; \quad I_{c}=8.20 \mathrm{ma} / \mathrm{cm}^{2} ; \\
I_{a}=8.10 \mathrm{ma} / \mathrm{cm}^{2}\end{array}$} \\
\hline 1 & -6.3 & -6.4 & -0.1 & 6.3 & 6 & 0 \\
\hline- & & -1 & & 12.9 & & \\
\hline 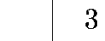 & -19.7 & -20.3 & -0.6 & 19.8 & 20 & 0.5 \\
\hline 4 & -27.5 & -28.9 & -1.4 & 27.7 & 28 & 1 \\
\hline 5 & -36.5 & -39.7 & -3.2 & 36.9 & 39 & 2.8 \\
\hline 6 & -48.1 & -53.9 & -5.8 & 48.8 & 53.9 & 5.1 \\
\hline
\end{tabular}

\begin{tabular}{|c|c|c|c|c|c|c|c|}
\hline \multicolumn{8}{|c|}{$\begin{array}{c}102 \mathrm{rpm} ; V=26.8 \mathrm{~cm} / \mathrm{sec} ; \quad I_{c}=3.96 \mathrm{ma} / \mathrm{cm}^{2} ; \\
I_{a}=3.80 \mathrm{ma} / \mathrm{cm}^{2}\end{array}$} \\
\hline \multirow{12}{*}{$15 \mathrm{c}$} & 0.3 & -4.0 & -4.0 & 0.0 & 4.0 & 4.0 & 0.0 \\
\hline & 0.6 & -8.0 & -7.9 & 0.1 & 8.0 & 7.9 & -0.1 \\
\hline & 0.9 & -12.1 & -12.1 & 0.0 & 12.2 & 12.1 & -0.1 \\
\hline & 1.2 & -16.3 & -16.7 & -0.4 & 16.6 & 16.7 & 0.1 \\
\hline & 1.5 & -20.8 & -20.9 & -0.1 & 21.1 & 20.9 & -0.2 \\
\hline & 1.8 & -25.5 & -26.0 & -0.5 & 26.1 & 26.0 & -0.1 \\
\hline & 2.1 & -30.7 & -31.2 & -0.5 & 31.6 & 31.2 & -0.4 \\
\hline & 2.4 & -36.6 & -37.1 & -0.5 & 37.9 & 37.1 & -0.8 \\
\hline & 2.7 & -43.3 & -44.2 & -0.9 & 45.2 & 44.2 & -1.0 \\
\hline & 3.0 & -51.4 & -54.2 & -2.8 & 54.5 & 54.2 & -0.3 \\
\hline & 3.3 & -62.1 & -68.0 & -5.9 & 67.7 & 68.0 & 0.3 \\
\hline & 3.36 & -64.8 & -71.0 & -6.2 & 71.3 & 71.0 & -0.3 \\
\hline \multicolumn{8}{|c|}{$\begin{array}{c}25 \mathrm{rpm} ; V=6.58 \mathrm{~cm} / \mathrm{sec} ; \quad I_{c}=1.81 \mathrm{ma} / \mathrm{cm}^{2} ; \\
I_{a}=1.74 \mathrm{ma} / \mathrm{cm}^{2}\end{array}$} \\
\hline \multirow[t]{8}{*}{$15 d$} & 0.2 & -5.8 & -6.2 & -0.4 & 5.8 & 6.2 & 0.4 \\
\hline & 0.4 & -11.7 & -1 & -0.4 & 11.8 & 12.1 & 0.3 \\
\hline & 0.6 & -17.8 & - & -0.7 & 17.8 & 18.5 & 0.7 \\
\hline & 0.8 & -24.7 & -2 & -0.6 & 25.2 & 25.3 & 0.1 \\
\hline & 1.0 & -32.3 & -3 & -0.7 & 33.3 & 33.0 & -0.3 \\
\hline & 1.2 & -41.4 & -4 & -1.2 & 43.1 & 42.6 & -0.5 \\
\hline & 1.4 & -53.3 & -55.2 & -1.9 & 56.7 & 57.0 & -0.3 \\
\hline & 1.5 & -61.2 & -64.7 & -3.5 & 66.3 & 68.7 & 2.4 \\
\hline
\end{tabular}




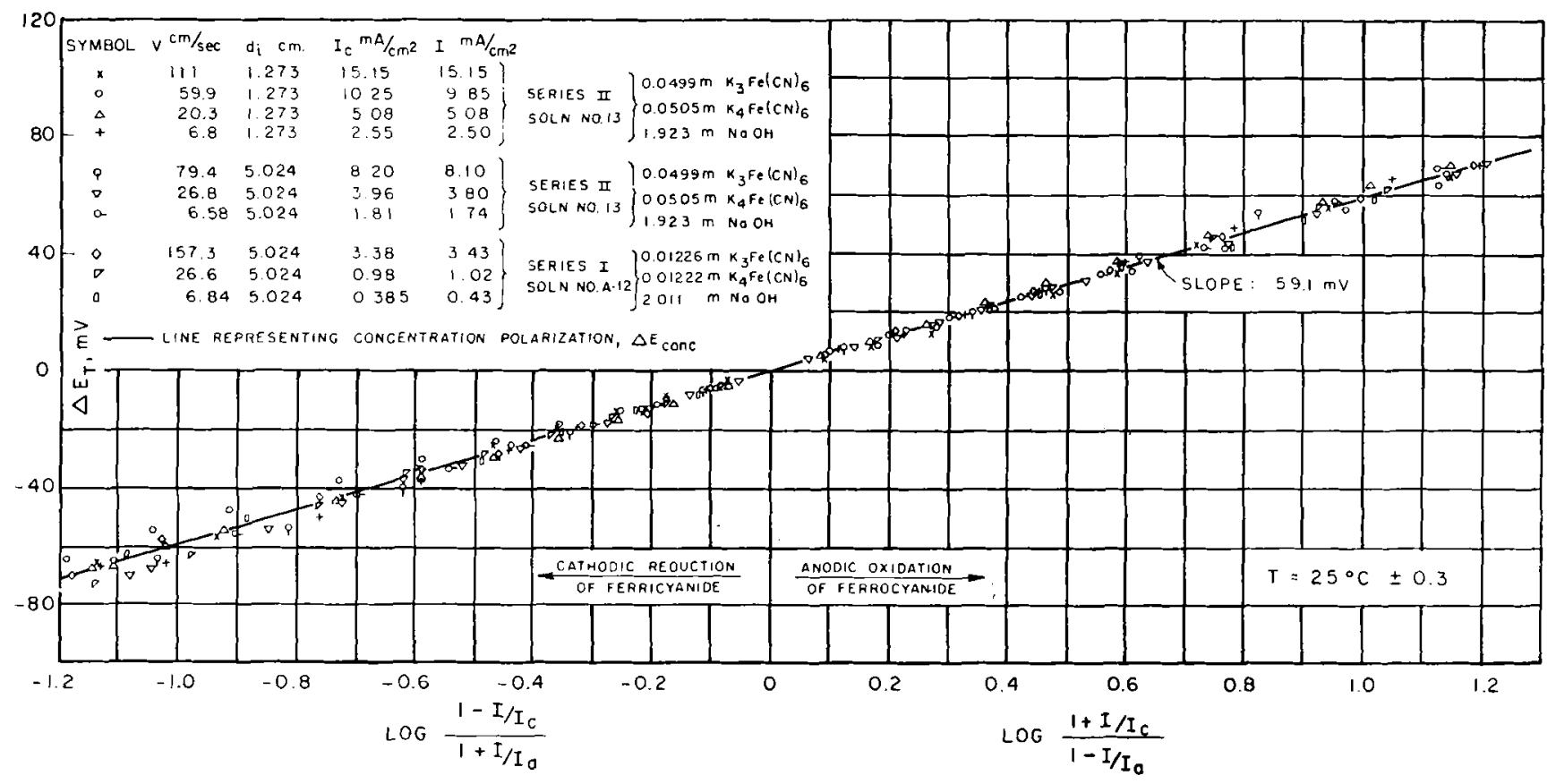

Fig. 11. Total polarization $\Delta E_{T}$ vs. $\log Q$

$i_{o}$ may be expected to decrease significantly under such conditions. In a special study on effects of better known electrode poisons, Gerischer (42) found that at platinum electrodes treated with a $2 \times 10^{-5} \mathrm{M} \mathrm{H}_{2} \mathrm{~S}$ solution for $1 \mathrm{~min}$ and $60 \mathrm{~min}$, respectively, $i_{0}$ for the $\mathrm{Fe}^{+3} / \mathrm{Fe}^{+2}$ couple dropped to $10.8 \%$ and $1.7 \%$ of the original (active state) value, respectively. The highly alkaline solutions used in the present studies, when exposed to air, could dissolve an amount of $\mathrm{H}_{2} \mathrm{~S}$ sufficient to decrease $i_{o}$ and consequently increase chemical polarization. Effects of other electrode poisons should, of course, be taken into account also. For instance, HCN formed through photochemical decomposition of ferrocyanide may exercise a powerful effect. Several investigators $(45,28)$ have also concluded that even electrodes made of "noble" metals such as gold, silver, and nickel become gradually covered with oxide films (when used in air-saturated solutions) causing a large increase in polarization.

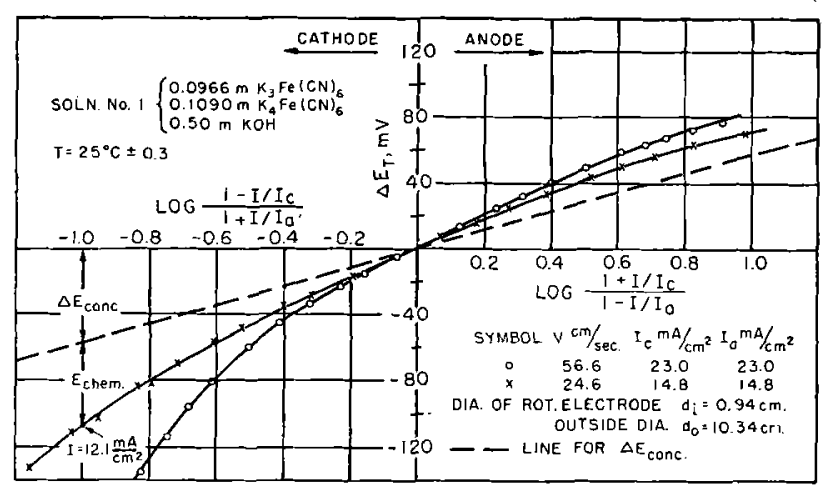

Fig. 12. Total polarization $\Delta E_{T}$ vs. $\log Q$ in case of "inactive electrodes" and presence of air-oxygen.
In a special study designed to demonstrate the effect of electrode poisons, $\Delta E_{T}-I$ data were obtained for an alkaline ferro- ferricyanide solution, which was exposed to air and light for several days. Nickel electrodes used in this study were cleaned in the same manner as described previously, but were not given any cathodic hydrogen discharge treatment. Fig. 12 shows the results for solution No. 1 in the form of $\Delta E_{T}$ vs. $\log Q$ plot. Large chemical polarizations (demonstrated by deviations from the $\Delta E_{\text {conc }}$ line) were obtained in spite of relatively low rotational speeds (up to $56.6 \mathrm{~cm} / \mathrm{sec}$ ). Values of $\Delta E_{\text {conc }}=-59.1 \mathrm{mv}$ and $\Delta E_{\text {chem }}=-47.9 \mathrm{mv}$ (hence $\Delta E_{T}=-107 \mathrm{mv}$ ) indicated in Fig. 12 (cathodic case) are for an applied C.D. of $12.1 \mathrm{ma} /$ $\mathrm{cm}^{2}$ and a peripheral speed of $24.6 \mathrm{~cm} / \mathrm{sec}$. It is interesting to compare these with a freshly prepared solution (number 9) at about the same C.D.

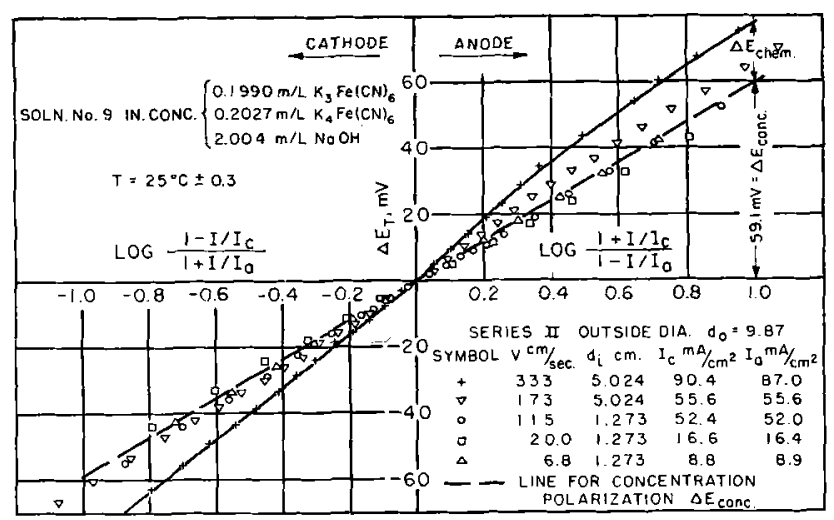

Fig. 13. Total polarization $\Delta E_{T}$ vs. $\log Q$ for high current density electrolysis. 
and rotational speed. ${ }^{16}$ Thus at a $I=12 \mathrm{ma} / \mathrm{cm}^{2}$ and $V=20 \mathrm{~cm} / \mathrm{sec}$, a total cathodic polarization $\left(\Delta E_{T}\right)$ of only $-43.5 \mathrm{mv}$ was measured for solution number $9 .{ }^{17}$ The corresponding concentration polarization was calculated to be $-47.1 \mathrm{mv} .^{18}$ Hence no measurable chemical polarization was determined in this case, while at the same C.D. in the case of the poisoned electrode, $\Delta E_{\text {chem }}$ represented about $45 \%$ of total electrode polarization.

With regard to the ferro- ferricyanide couple the following conclusions may be drawn on the basis of the present study.

$(A)$ Only freshly prepared and deaerated alkaline potassium ferri- and ferrocyanide solutions should be used with a maximum possible exclusion of light. The electrode (platinum or nickel) should be given a cathodic hydrogen treatment prior to each experiment.

(B) With the above precaution a reasonably small $\Delta E_{\text {chem }}$ is associated with the electrolytic redox reaction. The amount of $\Delta E_{\text {chem }}$ involved depends on the magnitude of the $I_{a} / i_{o}$ ratio, i.e., on the rate of stirring (on which $I_{a}$ depends). For rotating electrodes up to a peripheral velocity of 115 $\mathrm{cm} / \mathrm{sec}$, the electrode reaction is predominantly mass transfer controlled and the chemical polarization is negligibly small. The above peripheral velocity corresponds to a Reynolds number of 11,000 . It should be reasonable to assume that in many other types of flow up to $R_{d}=11,000 \mathrm{a}$ negligible $\Delta E_{\text {chem }}$ may be expected for the ferriferrocyanide couple.

(C) Under conditions (see above) at which the total electrode polarization is almost entirely represented by concentration polarization, the general mass transfer correlation for rotating cylinders (equation VII) can be used to predict $\delta, I_{c}$, or $I_{a}$, and $\Delta E_{\text {cono }}$ (see equations $\mathrm{X}, \mathrm{XI}$, and IV). Conversely, from a given measured polarization, $c_{i}$ of the reacting ion may be calculated at an applied current density.

To illustrate the latter point, calculations of $\delta$, $I_{c}, I_{a}$, and $\Delta E_{\text {conc }}$ have been carried out below for a rotating electrode in an alkaline potassium ferroferricyanide solution. To facilitate comparison with

\footnotetext{
${ }^{16}$ The difference in concentrations of the reacting ions between solutions. number 1 and 9 (a factor of 2 ) does not significantly affect this comparison, primarily because the ratio $I_{a} / i_{o}$ is independent of the bulk concentration of the reacting ion.

${ }_{17}$ See footnote (15).

${ }^{18}$ Actually the absolute value of $\Delta E_{T}$ cannot be smaller than that of $\Delta E_{\text {conc. }}$. Whenever this seems to be the case, it must be attributed not only to experimental inaccuracies, but also to the possibility that achievement of a steady state polarization of the electrode was not quite complete. Fortunately in no case were these deviations very serious.
}

experimental measurements the physical data for one of the systems studied were used.

Illustrative example. Assumed solution: (Equivalent to solution No. 9) $0.1976 M \quad \mathrm{~K}_{3} \mathrm{Fe}(\mathrm{CN})_{6}$, $0.2027 M \mathrm{~K}_{4} \mathrm{Fe}(\mathrm{CN})_{6}, 2.004 M \mathrm{NaOH}$.

Data: $d_{i}=1.273 \mathrm{~cm} ; S=300 \mathrm{rpm} ; V=$ $\frac{S}{60} \pi d_{i}=\frac{300}{60} \times 3.1416 \times 1.273=20.0 \mathrm{~cm} / \mathrm{sec} ;$ $R_{d}=1,789$; temperature, $25^{\circ} \mathrm{C} ; \nu=1.423 \times$ $10^{-2} \mathrm{~cm}^{2} / \mathrm{sec} ; D_{\text {forri }}=0.454 \times 10^{-5} \mathrm{~cm}^{2} / \mathrm{sec}$; $D_{\text {ferro }}=0.390 \times 10^{-5} \mathrm{~cm}^{2} / \mathrm{sec} ; c_{\text {ferrj }}=0.1976 \times$ $10^{-3} \mathrm{moles} / \mathrm{cc} ; c_{\text {ferro }}=0.2027 \times 10^{-3} \mathrm{moles} / \mathrm{cc}$.

Diffusion Layer Thickness, $\delta$ : From equation (XI):

$$
\delta_{(\mathrm{cm})}=12.64 d_{i}^{0.30} V^{-0.70} \nu^{0.344} D^{0.356} .
$$

Hence for the cathodic case:

$$
\begin{aligned}
& \delta_{\text {ferri }}=12.64(1.273)^{0.30}(20.0)^{-0.70} \\
& \left(1.423 \times 10^{-2}\right)^{0.344}\left(0.454 \times 10^{-5}\right)^{0.356} \\
& =4.840 \times 10^{-3} \mathrm{~cm} \\
& \delta_{\mathrm{ferro}}=12.64(1.273)^{0.30}(20.0)^{-0.70} \\
& \left(1.423 \times 10^{-2}\right)^{0.344}\left(0.390 \times 10^{-5}\right)^{0.356} \\
& =4.585 \times 10^{-3} \mathrm{~cm} \\
& I_{c}=\frac{n \mathbf{F} D}{\delta} c_{\mathrm{ferri}} \\
& \frac{1 \times 96,500 \times\left(0.453 \times 10^{-5}\right)}{4.840 \times 10^{-3}} \times\left(0.1976 \times 10^{-3}\right) \\
& =17.89 \times 10^{-3} \mathrm{amp} / \mathrm{cm}^{2}=17.89 \mathrm{ma} / \mathrm{cm}^{2}
\end{aligned}
$$

as compared to experimentally determined

$$
\begin{aligned}
& I_{c}=16.6 \mathrm{ma} / \mathrm{cm}^{2} \\
& \text { Deviation }=7.6 \%
\end{aligned}
$$

Anodic limiting C.D.,

$I_{a}=\frac{n \mathrm{~F} D}{\delta_{\mathrm{ferro}}} c_{\mathrm{fcrro}}$

$$
=\frac{1 \times 96,500 \times\left(0.390 \times 10^{-5}\right)}{4.585 \times 10^{-3}} \times\left(0.2027 \times 10^{-3}\right)
$$$$
=16.64 \times 10^{-3} \mathrm{amp} / \mathrm{cm}^{2}=16.64 \mathrm{ma} / \mathrm{cm}^{2}
$$

as compared to experimentally determined

$$
\begin{aligned}
& I_{a}=16.4 \mathrm{ma} / \mathrm{cm}^{2} \\
& \text { Deviation }=1.5 \%
\end{aligned}
$$

Concentration Polarization at Applied C.D. of $10 \mathrm{ma} / \mathrm{cm}^{2}$ :

$$
\begin{aligned}
\text { Cathodic } \Delta E_{\text {canc }} & =59.1 \log \frac{1-I / I_{c}}{1+I / I_{a}} \\
& =59.1 \log \frac{1-10 / 17.89}{1+10 / 16.64} \\
& =-33.1 \mathrm{mv}
\end{aligned}
$$


as compared to the experimentally measured total cathodic polarization

$$
\begin{aligned}
\Delta E_{T} & =-33.0 \mathrm{mv} \\
\text { Anodic } \Delta E_{\mathrm{conc}} & =59.1 \log \frac{1+I / I_{c}}{1-I / \bar{I}_{a}} \\
& =59.1 \log \frac{1+10 / 17.89}{1-10 / 16.64} \\
& =+34.9 \mathrm{mv}
\end{aligned}
$$

as compared to the experimentally measured total anodic polarization

$$
\Delta E_{T}=32.8 \mathrm{mv}
$$

Hence chemical polarization is negligible for these cathodic and anodic runs, and prediction of $\Delta E_{T}$ is possible. It should be noted that the general mass transfer correlation enables prediction of limiting currents and concentration polarization even when chemical polarization is large; however, then the total electrode polarization could not be calculated.

The ferro-ferricyanide couple can thus be used conveniently to study mass transfer in liquids for various types of geometries and hydrodynamic conditions. The advantages of using an electrolytic redox reaction over solid dissolution for purposes of studying rates of mass transfer are: $(a)$ achievement of steady state in a relatively short time; $(b)$ direct control of rates, i.e., applied current (This is not possible in case of solids.); (c) preservation of smooth interfacial surface throughout the experiment; $(d)$ higher accuracy and convenience in determination of rates of mass transfer.

The present study has proved that, when properly carried out, the ferro-ferricyanide electrode reactions may be considered to remain predominantly under mass transfer control up to stirring rates corresponding to $R_{d}=11,000$. However, chemical polarization is essentially present whenever finite currents are passed, and becomes significant at high stirring rates. The reason Essin and coworkers (30) could claim that electrolytic reactions of the ferri-ferrocyanide couple involve only concentration polarization is that their experiments were carried out at low stirring rates.

Under proper experimental conditions, when concentration polarization is accounted for, the ferri-ferrocyanide couple is not far from thermodynamic equilibrium, i.e., $\Delta F^{*}$ is not very large. For the electrochemical reaction which takes place at the electrode interface itself, Lewartowicz (43) discussed two rate-determining steps. One step involves electron transfer at the interface of the electrode, the other the change in hydration of the ion under- going recharge. For the ferri-ferrocyanide couple this may be expressed as:

$$
\begin{aligned}
\mathrm{Fe}(\mathrm{CN})_{6}^{-3}\left(\mathrm{H}_{2} \mathrm{O}\right)_{m}+e^{-} & \\
& \rightleftarrows \mathrm{Fe}(\mathrm{CN})_{6}^{-4}\left(\mathrm{H}_{2} \mathrm{O}\right)_{n}+(m-n) \mathrm{H}_{2} \mathrm{O}
\end{aligned}
$$

Numerous investigators (46-48) have found that an ion is more hydrated the larger its charge and the smaller its radius. Hence, activation energy of the total process is composed of energy necessary for electron passage between ion and electrode and of hydration energy. The latter depends only on the state of hydration of oxidized and reduced ions, but the former is probably the one which is affected by presence of electrolytic poisons adsorbed at the electrode surface. Lewartowicz's experiments (43) on $\mathrm{Fe}^{+3} / \mathrm{Fe}^{+2}, \mathrm{Ce}^{+4} / \mathrm{Ce}^{+3}$ and quinone/hydroquinone couples have shown a small chemical polarization to be involved in each case. His results support in a general sense the above discussed mechanism of the electrolytic redox reaction.

It seems reasonable that electrode reactions involving only electron transfer and change in degree of ion hydration would involve small activation energies, compared to reactions involving breaking or formation of chemical bonds.

\section{ACKNOWLEDGMent}

The authors wish to acknowledge the support of the Office of Naval Research. Appreciation is due to Mr. Lawrence Wolf and Mr. James Worley for assistance with experimental measurements.

Any discussion of this paper will appear in a Discussion Section to be published in the December 1954 issue of the JoURnat.

\section{REFERENCES}

1. M. Ersenberg, "Studies on the Role of Ionic Diffusion and Mass Transfer in Electrode Processes," M.S. Thesis, University of California, Berkeley (1951).

2. C. W. Tomias, M. Eisenbera, and C. R. Wilke, This Journal, 99, 359C (1952).

3. C. WAGNeR, ibid., 95, 161 (1949).

4. C. R. Wilke, M. Eisenberg, and C. W. Tobias, ibid., 100, $513(1953)$.

5. B. Levich, Acta Physicochim. U.R.S.S., 17, 257 (1942).

6. J. N. Agar, Disc. Faraday Soc., 1, 26 (1947).

7. C. S. Lin, E. B. Denton, N. S. Gaskili, and G. L. Putnam, Ind. Eng. Chem., 45, 2136 (1951).

8. C. S. Lin, R. W. Moulton, and G. L. Putnam, Ind. Eng. Chem., 45, 636 (1953).

9. G. I. TAYLOR, Phil. Trans. Roy. Soc. London, 223, 289 (1923); Proc. Roy. Soc. London, A151, 494 (1935).

10. Shin-I Pat, NACA Tech. Note 892 (1943).

11. T. Theodorsen and A. Regier, NACA Report 793 (1945).

12. I. M. Kolthoff and J. J. Lingane, "Polarography," 2nd ed., Interscience Publishing Co., New York (1952).

13. T. Tsukamoto, T. Kambara, and I. Tachi, J. Electrochem. Assoc. Japan, 18, 386 (1950). 
14. E. Brunner, Z. physik. Chem., 47, 56 (1904).

15. W. Nernst and E. S. Merriam, Z. physik. Chem., 53, 235 (1905).

16. A. Eucken, Z. Elektrochem., 38, 341 (1932).

17. T. Kambara and T. Tsukamoto, $J$, Electrochem. Assoc. Japan, 18, 356 (1950).

18. B. Roald and W. Brek, This Journal, 98, 277 (1951).

19. H. Salzberg and C. V. KING, ibid., 97, 290 (1950).

20. C. V. King and F. S. Lang, ibid., 99, 295 (1952).

21. C. V. King AND N. MaYer, ibid., 100, 473 (1953).

22. R. Glicksman, H. Modquin, and C. V. King, ibid., $100,580(1953)$.

23. C. V. King and M. Shack, J. Am. Chem. Soc., 57, $1212(1935)$

24. C. V. King and W. H. Catheart, ibid., 59, 63 (1937).

25. C. V. King and P. L. Howard, Ind. Eng. Chem., 29, 75 (1937).

26. C. Fredenhagen, $Z$. anorg. Chem., 29, 396 (1902).

27. G. Jusr, Z. physik. Chem., 63, 513 (1908).

28. G. Grube, Z. Elektrochem., 18, 189 (1912); 20, 334 (1914).

29. W. L. H. Moll, Z. physik. Chem., A175, 353 (1936).

30. O. Essin, S. Derendrayer, and N. Ladygin, J. Appl. Chem. (U. R. S. S.), 13, 971 (1940).

31. W. R. Carmody and J. J. Rohan, Trans. Electrochem. Soc., 83, 241 (1943).

32. J. V. Petrocelli and A. A. Paolucci, This Journal, 98, 291 (1951).
33. J. Ma TuscheK, Chem. Ztg., 25, 601 (1901).

34. S. IImori, $Z$. anorg. u. allgem. Chem., 167, 145 (1927).

35. I. M. Kolthoff and E. A. Pearson, Ind. Eng. Chem., Anal. Ed., 3, 381 (1931).

36. I. M. Kolthoff and N. H. Furman, "Volumetric Analysis," Vol. II, p. 427, J. Wiley and Sons, New York (1929).

37. F. Surton, "Volumetric Analysis," 1.2th ed., p. 235, Blakiston and Co., Philadelphia (1935).

38. J. S. Anderson and K. Saddington, J. Chem. Soc., 1949, S381.

39. M. Ersenberg, C. W. Tobias, and C. R. Wilke, Technical Report No. 2, Nonr 222 (06). To be published in Chem. Eng. Progr. in 1954.

40. J. V. Petrocelli, This Journal, 98, 187 (1951).

41. T. H. Chilton and A. P. Colburn, Ind. Eng. Chem., 26, 1183 (1934).

42. H. Gerischer, Z. Elektrochem., 54, 362 (1950); 55, 98 (1951).

43. E. Lewartowicz, $J$, chim. phys., 49, 557, 564, 573 (1952).

44. H. Eyring, S. Glasstone, and K. J. Laidler, $J$. Chem. Phys., 7, 1053 (1939).

45. M. Le Blanc, Abhandl. Bunsen Ges., No. 3 (1910).

46. H. Brinteinger and Ch. Ratranarat, $Z$. anorg. $u$. ailgem. Chem., 222, 113 (1935).

47. H. SACHsse, Z. Elektrochem., 40, 531 (1934).

48. G. Sutra, J. chim. phys., 43, 189 (1946). 


\section{Nomenclature}

\begin{tabular}{|c|c|c|}
\hline Symbol & Definition & Units \\
\hline$c_{o}$ & $\begin{array}{l}\text { Concentration of reacting } \\
\text { ions in the bulk of the } \\
\text { solution }\end{array}$ & mole/cc \\
\hline$c_{i}$ & $\begin{array}{l}\text { Concentration of reacting } \\
\text { ions at the electrode in- } \\
\text { terface }\end{array}$ & mole/cc \\
\hline$c_{\text {ferri }}$ & $\begin{array}{l}\text { Bulk concentration of fer- } \\
\text { ricyanide ions }\end{array}$ & mole/cc \\
\hline$c_{\text {ferro }}$ & $\begin{array}{l}\text { Bulk concentration of fer- } \\
\text { rocyanide ions }\end{array}$ & mole/co \\
\hline$d_{i}$ & $\begin{array}{l}\text { Diameter of the inner ro- } \\
\text { tating electrode }\end{array}$ & $\mathrm{cm}$ \\
\hline$D$ & $\begin{array}{l}\text { Diffusion coefficient of } \\
\text { species } k\end{array}$ & $\mathrm{~cm}^{2} / \mathrm{sec}$ \\
\hline$\Delta E_{T}$ & Total polarization & $\mathrm{mv}$ \\
\hline$\Delta E_{\text {conc }}$ & Concentration polarization & $\mathrm{mv}$ \\
\hline$\Delta E_{\text {cliem }}$ & Chemical polarization & $\mathrm{mv}$ \\
\hline$f$ & Friction factor & $\begin{array}{l}\text { dimension- } \\
\text { less }\end{array}$ \\
\hline $\mathbf{F}$ & Faraday equivalent & $\begin{array}{l}96,500 \text { cou- } \\
\text { lomb/equiv }\end{array}$ \\
\hline$\Delta F^{*}$ & $\begin{array}{l}\text { Standard free energy } \\
\text { change of activation }\end{array}$ & ergs/mole \\
\hline$h$ & Planck constant & $\begin{array}{l}6.624 \times 10^{-27} \\
\text { erg-sec } / \\
\text { molecule }\end{array}$ \\
\hline$h^{\prime}$ & Height of cell & $\mathrm{cm}$ \\
\hline$i$ & Total current & $a m p$ \\
\hline$i_{o}$ & Exchange current density & $\mathrm{amp} / \mathrm{cm}^{2}$ \\
\hline$I$ & Current density & $\mathrm{ma} / \mathrm{cm}^{2}$ \\
\hline$I_{a}$ & $\begin{array}{l}\text { Anodic limiting current } \\
\text { density }\end{array}$ & $\mathrm{ma} / \mathrm{cm}^{2}$ \\
\hline$I_{c}$ & $\begin{array}{l}\text { Cathodic limiting current } \\
\text { density }\end{array}$ & $\mathrm{ma} / \mathrm{cm}^{2}$ \\
\hline$I_{L}$ & $\begin{array}{l}\text { Limiting current current } \\
\text { density, generally }\end{array}$ & $\operatorname{amp} / \mathrm{cm}^{2}$ \\
\hline$\dot{j}_{D}^{\prime}$ & $\begin{array}{l}\text { Modified Chilton-Colburn } \\
\text { j-number }\end{array}$ & $\begin{array}{l}\text { dimension- } \\
\text { less }\end{array}$ \\
\hline$k$ & $\begin{array}{l}\text { Boltzmann } \\
1.3805 \times 10^{-6}\end{array}$ & $\begin{array}{l}\text { erg } /^{\circ} \mathrm{K} \\
\text { molecule }\end{array}$ \\
\hline$k_{a}$ & $\begin{array}{l}\text { Mass transfer coefficient at } \\
\text { the anode }\end{array}$ & $\mathrm{cm} / \mathrm{sec}$ \\
\hline$k_{c}$ & $\begin{array}{l}\text { Mass transfer coefficient at } \\
\text { the cathode }\end{array}$ & $\mathrm{cm} / \mathrm{sec}$ \\
\hline$k_{L}$ & $\begin{array}{l}\text { Mass transfer coefficient, } \\
\text { generally }\end{array}$ & $\mathrm{cm} / \mathrm{sec}$ \\
\hline$n$ & $\begin{array}{l}\text { Number of electrons ex- } \\
\text { changed in electrode re- } \\
\text { action }\end{array}$ & \\
\hline
\end{tabular}

NOMENCLATURE-Continued

\begin{tabular}{|c|c|c|}
\hline Symbol & Definition & Units \\
\hline$N$ & Rate of mass transfer & $\begin{array}{l}\text { mole } / \mathrm{cm}^{2}- \\
\quad \text { sec }\end{array}$ \\
\hline$r_{i}$ & $\begin{array}{l}\text { Radius of rotated inner } \\
\text { electrode }\end{array}$ & $\mathrm{cm}$ \\
\hline$r_{0}$ & $\begin{array}{l}\text { Internal radius of outer } \\
\text { electrode }\end{array}$ & $\mathrm{cm}$ \\
\hline$R_{(1)}, R_{(2)}$ & Resistance & ohms \\
\hline$R$ & Universal gas constant & $\begin{array}{l}8.313 \times 10^{7} \\
\text { erg/ } /^{\circ} \mathrm{K}- \\
\text { mole }\end{array}$ \\
\hline$t_{i}$ & $\begin{array}{l}\text { Transference number of } \\
\text { the reacting ion }\end{array}$ & \\
\hline$T$ & Temperature & ${ }^{\circ} \mathrm{K}$ \\
\hline$V$ & $\begin{array}{l}\text { Peripheral velocity at the } \\
\text { rotating cylinder }\end{array}$ & $\mathrm{cm} / \mathrm{sec}$ \\
\hline$Z C P$ & $\begin{array}{l}\text { Zero current potential } \\
\text { (static potential differ- } \\
\text { ence between an inves- } \\
\text { tigated electrode and the } \\
\text { reference cell) }\end{array}$ & $\mathrm{mv}$ \\
\hline \multicolumn{3}{|c|}{ Greek symbols } \\
\hline$\alpha, \beta$ & $\begin{array}{l}\text { Fractions of electrical po- } \\
\text { tential difference across } \\
\text { the activation energy } \\
\text { barrier acting in the } \\
\text { cathodic and anodic di- } \\
\text { rection respectively }\end{array}$ & \\
\hline$\delta$ & Thickness of diffusion layer & $\mathrm{cm}$ \\
\hline$\kappa$ & $\begin{array}{l}\text { Electrical conductivity of } \\
\text { a solution }\end{array}$ & $\mathrm{ohm}^{-1} \mathrm{~cm}^{-1}$ \\
\hline$\mu$ & Dynamic viscosity & $\mathrm{g} / \mathrm{cm}-\mathrm{sec}$ \\
\hline$\nu$ & Kinematic viscosity & $\mathrm{cm}^{2} / \mathrm{sec}$ \\
\hline$\rho$ & Density & $\mathrm{g} / \mathrm{cm}^{3}$ \\
\hline
\end{tabular}

Dimensionless groups

\begin{tabular}{|c|c|}
\hline$Q=\frac{1 \mp I / I_{c}}{1 \pm I / I_{a}}$ & $\begin{array}{l}\text { Ratio used in } \Delta E_{\text {conc }} \text { calcu- } \\
\text { lations (upper sign for } \\
\text { cathodic case, lower for } \\
\text { anodic) }\end{array}$ \\
\hline$R_{d}=\frac{V d_{i}}{\nu}$ & $\begin{array}{l}\text { Reynolds number based on } \\
\text { diameter of rotating in- } \\
\text { ner eylinder }\end{array}$ \\
\hline$S c=\frac{\nu}{D_{k}}$ & $\begin{array}{l}\text { Schmidt number for mass } \\
\text { transfer of species } k\end{array}$ \\
\hline
\end{tabular}

